\title{
Arranjo de plantas e número de sementes por cova na produção agroeconômica de ervilha
}

\section{Plants arrangement and number of seeds per hole in the agroeconomic yield of pea}

\author{
Elissandra Pacito Torales ${ }^{1 *}$; Néstor Antonio Heredia Zárate ${ }^{2}$; \\ Maria do Carmo Vieira ${ }^{2}$; Robson Santos Gutierrez ${ }^{3}$; \\ Rosimeire Pereira Gassi ${ }^{4}$; Luciane Almeri Tabaldi ${ }^{5}$
}

\section{Resumo}

O objetivo deste trabalho foi estudar a ervilha 'Luciana 50', cultivada sob diferentes números de fileiras de plantas no canteiro e com duas e três sementes por cova. O trabalho foi desenvolvido em DouradosMS, entre março e julho de 2010. Os tratamentos foram arranjados no esquema fatorial 3 × 2 no delineamento experimental de blocos casualizados, com seis repetições. As populações correspondentes à semeadura com duas, três e quatro fileiras no canteiro foram de $264.000,396.000$ e 528.000 plantas ha $^{-1}$, respectivamente, com duas sementes por cova, e de 396.000, 594.000 e 792.000 plantas ha ${ }^{-1}$, respectivamente, com três sementes por cova. A colheita foi realizada aos 108 dias após a semeadura. No cultivo com quatro fileiras de plantas e duas sementes por cova, obtiveram-se as maiores produções de massa fresca e massa seca de grãos e vagem comercial, com aumentos de $29,88 \%, 33,85 \%, 29,14 \%$ e $32,22 \%$, respectivamente, e maiores números de grãos e vagens comerciais, com aumentos de $28,13 \%$ e $27,12 \%$, respectivamente, em relação a duas fileiras de plantas com duas sementes por cova. As maiores produções de massa fresca da parte aérea, de cascas e de vagens não-comerciais foram com quatro fileiras de plantas, com aumentos de $1,75 \mathrm{Mg} \mathrm{ha}^{-1}, 0,44 \mathrm{Mg} \mathrm{ha}^{-1}$ e $0,47 \mathrm{Mg} \mathrm{ha}^{-1}$ respectivamente, em relação a duas fileiras. Considerando a produtividade de vagens e grãos comerciais e a estimativa da renda líquida, pode-se concluir que a semeadura de ervilha 'Luciana 50' deve ser realizada com quatro fileiras de plantas e com duas sementes por cova.

Palavras-chave: Pisum sativum, produtividade, populações de plantas

\begin{abstract}
The aim of this work was to study the 'luciana 50' pea, cultivated with different numbers of rows of plants in the plot and with two and three seeds per hill. The work carried out in Dourados-MS, between March-July 2010. Treatments were arranged in $3 \times 2$ factorial in randomized complete block design with six replicates. Populations corresponding to the sowing with two, three and four rows per plot were 264,000, 396,000 and 528,000 plants ha ${ }^{-1}$, respectively, with two seeds per hill, and 396,000, 594,000 and 792,000 plants ha ${ }^{-1}$, respectively, with three seeds per hill. The harvest was done at 108 days after sowing. In cultivation with four rows of plants and two seeds per hill, were obtained the highest yields of fresh and dry weight of grains and pods commercial, with increases of $29.88 \%, 33.85 \%, 29.14 \%$ and $32.22 \%$, respectively, and higher number of grains and pods commercial, with increases of $28.13 \%$ and

\footnotetext{
${ }^{1}$ Pós-Doutoranda, Universidade Federal da Grande Dourados, UFGD, Dourados, MS. E-mail: ninapacito@hotmail.com

2 Profs., UFGD, Dourados, MS. E-mail: nestorzarate@ufgd.edu.br; mariavieira@ufgd.edu.br

3 Discente de Mestrado, UFGD, Dourados, MS. E-mail: agrogrilo@hotmail.com

4 Pós-Doutorado, UFGD, Dourados, MS. E-mail: rpgassi@yahoo.com.br

${ }^{5}$ Prof ${ }^{a}$, Universidade Federal de Santa Maria, UFSM, Santa Maria, RS. E-mail: lutabaldi@yahoo.com.br Autor para correspondência
} 
$27.12 \%$, respectively, over two rows of plants with two seeds per hill. The highest yield of fresh weight of shoots, of bark and of non-commercial pods were with four rows of plants, with increases of 1.75 $\mathrm{Mg} \mathrm{ha}^{-1}, 0.44 \mathrm{Mg} \mathrm{ha}^{-1}$ and $0.47 \mathrm{Mg} \mathrm{ha}^{-1}$ respectively, compared to two rows. Considering the yield of commercial pods and grains and the estimated net income, it can be concluded that sowing of 'Luciana 50 ' pea should be performed with four rows of plants and two seeds per hill.

Key words: Pisum sativum, productivity, plant populations

\section{Introdução}

A ervilha (Pisum sativum L, Fabaceae) é originária do Oriente Médio e muito apreciada em todo o mundo como legume, sendo consumida como grãos verdes ou grãos enlatados (secos reidratados ou verdes). No Brasil, até os anos oitenta, o produto era quase totalmente importado enquanto que atualmente, toda a demanda pode ser atendida pela produção nacional (IAC, 2011). A ervilha-verde é uma opção de produção para atender às novas demandas do mercado, principalmente de produtos supergelados (EMBRAPA, 2012).

Ao contrário da ervilha para produção de grãos secos que são reidratados e enlatados, as cultivares de ervilha-verde são próprias para colheita de grãos verdes, visando ao imediato congelamento e/ou enlatamento. O produto pode também ser comercializado na forma de vagens para debulhar ou de grãos debulhados, para consumo in natura (EMBRAPA, 2012).

O interesse na produção de ervilha, cultivada de maio a setembro, tem crescido não só devido ao seu alto valor nutritivo e das amplas alternativas de uso na alimentação, mas também por ser uma opção viável de cultivo a ser utilizada em programas de rotação de culturas (VIEIRA; RESENDE e SANTOS, 2000). No Brasil, a cultura da ervilha é realizada em locais de temperaturas amenas ou frias, adaptando-se às condições de outono-inverno, no Centro-Sul (FILGUEIRA, 2008).

Para se obter melhores produtividades, torna-se necessário estudar também outros tipos de tratos culturais, dentre os quais, o arranjo de plantas, o qual pode ser manipulado por meio de alterações na densidade de plantio. O melhor arranjo populacional, teoricamente, é aquele que proporciona distribuição mais uniforme de plantas por área, possibilitando melhor utilização de luz, água e nutrientes (ARGENTA et al., 2001). Isso ocorre porque a maximização da produção depende, dentre outros fatores, da população empregada, do índice e da duração da área foliar fotossinteticamente ativa, da prolificidade do cultivar, da época de semeadura visando satisfazer a cinética de desenvolvimento e crescimento, bem como a distribuição espacial adequada de plantas na área, em conformidade com as características genotípicas (HEREDIA ZÁRATE et al., 2009).

A densidade de semeadura é um fator importante e influencia diretamente o desenvolvimento e a produtividade da ervilha de vagens comestíveis (ISLAM et al., 2002). Heredia Zárate et al. (2012) avaliando agroeconomicamente a cultivar de ervilha Luciana ${ }^{\circ}{ }^{\circ} 50$, cultivada sob três espaçamentos entre plantas $(5,0 ; 7,5$ e $10,0 \mathrm{~cm})$, com e sem cobertura do solo com cama-de-frango, obtiveram maiores produtividades de grãos comerciais $\left(2,24 \mathrm{Mg} \mathrm{ha}^{-1}\right)$ e maior renda bruta $(\mathrm{R} \$ 12.900,00)$ e líquida $(\mathrm{R} \$$ $5.145,60)$, quando cultivada com espaçamento de $5,0 \mathrm{~cm}$ entre plantas dentro das fileiras. Gassi et al. (2009), estudando a capacidade produtiva da mesma cultivar de ervilha, cultivada sob quatro e cinco fileiras no canteiro e três espaçamentos entre plantas $(5,0 ; 7,5$ e $10,0 \mathrm{~cm})$, obtiveram maior produtividade de grãos tenros $\left(4,39 \mathrm{Mg} \mathrm{ha}^{-1}\right)$ e maior renda bruta (R\$ 21.950,00) no cultivo com quatro fileiras de plantas no canteiro e com $10 \mathrm{~cm}$ entre plantas.

Em qualquer atividade econômica, principalmente na agrícola, é essencial o estudo da rentabilidade e o acompanhamento de custos (MELO et al., 2009). A competitividade é a capacidade de inserir um produto da cadeia produtiva em vantagem comparativa em determinado mercado consumidor. 
Desse modo, os custos envolvidos na produção agrícola, em se tratando de competitividade, podem ser determinantes do sucesso ou do fracasso do produtor rural. Isso porque a rentabilidade consiste, em geral, na comparação da receita com o custo de produção, o que determina o lucro. Só haverá lucro se a atividade produtiva proporcionar retorno que supere o custo alternativo, conforme proposto por Silva et al. (2001), citado por Terra et al. (2006).

Dessa forma, objetivou-se avaliar a produtividade agroeconômica da ervilha cultivar 'Luciana 50', cultivada com diferentes arranjos de plantas no canteiro e sementes cova ${ }^{-1}$ para a região de Dourados-MS.

\section{Material e Métodos}

O experimento foi conduzido em área do Horto de Plantas Medicinais (HPM), da Faculdade de Ciências Agrárias - FCA, da Universidade Federal da Grande Dourados - UFGD, em Dourados - MS, entre março a julho de 2010. A área experimental situa-se em latitude de $22^{\circ} 11^{\prime} 44^{\prime \prime} S$, longitude de 54 56'08'W e altitude de $430 \mathrm{~m}$. O clima da região, segundo a classificação de Köppen é Mesotérmico Úmido, do tipo Cwa, com temperaturas e precipitações médias anuais variando de 20 a $24{ }^{\circ} \mathrm{C}$ e de 1250 a $1500 \mathrm{~mm}$, respectivamente. O solo é do tipo Latossolo Vermelho distroférrico, de textura muito argilosa (EMBRAPA, 2006).

O solo foi preparado duas semanas antes da semeadura, com uma aração e uma gradagem e, posteriormente, foram levantados os canteiros com rotoencanteirador. Para a semeadura, foram abertos sulcos de aproximadamente $0,05 \mathrm{~m}$ de largura $\mathrm{x}$ $0,05 \mathrm{~m}$ de profundidade, onde foram semeadas manualmente as sementes da cultivar Luciana 50. Como tratos culturais foram feitas irrigações utilizando o sistema de aspersão, sendo que na fase inicial, até quando as plantas apresentavam entre 15 a $20 \mathrm{~cm}$ de altura, os turnos de rega foram a cada dois dias e, posteriormente, os turnos de rega foram a cada três ou quatro dias e nos dias restantes, até efetuar a colheita, foram feitas uma vez por semana. O controle das plantas infestantes foi feito com enxada entre os canteiros, e manualmente, dentro dos canteiros. Não houve ocorrência de pragas ou doenças.

A colheita foi realizada aos 108 dias após a semeadura, quando as plantas apresentavam mais de $50 \%$ da senescência foliar, época em que foram avaliadas as seguintes características: produtividades de massa fresca e seca (massa obtida após a secagem do material em estufa com ventilação forçada de ar, por 72 horas, à temperatura de $60^{\circ} \mathrm{C} \pm$ $2{ }^{\circ} \mathrm{C}$ ) da parte aérea, de vagens comerciais (casca e grãos) e não-comerciais. Foram consideradas como vagens comerciais as que se apresentavam sadias e com os grãos bem desenvolvidos, classificadas visualmente. Foram consideradas vagens nãocomerciais aquelas murchas por deficiência de água e as que apresentavam sintomas de doenças ou brotadas, classificadas visualmente. Também foram determinados os números de vagens e de grãos comerciais e não-comerciais, o comprimento e diâmetro das vagens comerciais e diâmetro dos grãos.

O delineamento experimental foi em blocos ao acaso em esquema fatorial $3 \times 2$ (2, 3 e 4 fileiras no canteiro $\times 2$ e 3 sementes cova ${ }^{-1}$ ) totalizando seis tratamentos com seis repetições.

As populações correspondentes a semeadura com diferentes arranjos de plantas (duas, três e quatro fileiras no canteiro) foram de 264.000, 396.000 e 528.000 plantas ha $^{-1}$, respectivamente, com duas sementes por cova, e de 396.000, 594.000 e 792.000 plantas ha $^{-1}$, respectivamente, com três sementes por cova. O espaçamento entre covas da mesma linha foi de $0,10 \mathrm{~m}$. As parcelas tinham área total de $3,75 \mathrm{~m}^{2}$ (1,50 $\mathrm{m}$ de largura por $2,50 \mathrm{~m}$ de comprimento) e área útil de $2,50 \mathrm{~m}^{2}$ (canteiro de 1,0 $\mathrm{m}$ de largura e 2,50 $\mathrm{m}$ de comprimento).

Os dados de produtividade foram submetidos à analise de variância e quando se detectaram diferenças significativas pelo teste $\mathrm{F}$, as médias 
dos dados dos diferentes componentes das plantas foram comparadas pelo teste de Tukey, a 5\% de probabilidade.

As estimativas do custo de produção e das rendas bruta e líquida foram realizadas considerando as produtividades de massa fresca de grãos e vagens comerciais de ervilha, para cada tratamento. Para determinar o custo da mão-de-obra foi considerada a quantidade de dias/homem gastos para a realização de cada atividade multiplicada pelo valor diário pago em Dourados-MS para a mãode-obra temporária ( $\mathrm{R} \$ 25,00 \mathrm{D} / \mathrm{H})$. $\mathrm{O}$ custo com maquinários incluindo bomba de irrigação e trator foi efetuado pelo registro das horas utilizadas para a realização dos trabalhos necessários em cada operação e posterior conversão para hora/máquina por hectare e feita a multiplicação pelo valor das horas de uso de cada maquinário. Para o cálculo da renda bruta, foram utilizados os preços pagos ao agricultor de Dourados-MS, em janeiro de 2011, por quilograma de grão verde de ervilha $(\mathrm{R} \$ 10,00$ $\mathrm{kg}^{-1}$ ) e de vagem comercial $\left(\mathrm{R} \$ 5,00 \mathrm{~kg}^{-1}\right)$. A renda líquida foi determinada pela renda bruta menos os custos de produção por hectare cultivado.

\section{Resultados e Discussão}

\section{Produtividade}

As produtividades de massa fresca e massa seca de grãos comerciais, massa fresca e massa seca de vagens comerciais, número de vagens comerciais e número de grãos comerciais foram influenciadas significativamente pela interação número de fileiras no canteiro e número de sementes cova ${ }^{-1}$ (Tabela 1 ). Os maiores valores foram obtidos no cultivo com 2 sementes cova-1 e quatro fileiras de plantas, com aumentos na massa fresca e massa seca de grãos comerciais, e massa fresca e massa seca de vagens comerciais, de 0,75 $\mathrm{Mg} \mathrm{ha}^{-1}(+29,88 \%), 1,46 \mathrm{Mg} \mathrm{ha}^{-1}$ $(+33,85 \%), 0,22 \mathrm{Mg} \mathrm{ha}^{-1}(+29,14 \%)$ e $0,29 \mathrm{Mg} \mathrm{ha}^{-1}$ $(+32,22 \%)$, respectivamente, e maiores números de grãos comerciais e de vagens comerciais, com aumentos de $1.240 .000 \mathrm{ha}^{-1}(+28,13 \%)$ e 249.960 ha $^{-1}(+27,12 \%)$, respectivamente, em relação a duas fileiras de plantas e 2 sementes $\operatorname{cova}^{-1}$, que foi o tratamento com as menores médias.

A densidade de plantas na linha é um fator modificador da arquitetura da planta permitindo que estas se adaptem a diferentes condições (PEIXOTO et al., 2008). Esses aumentos nas produtividades dos diferentes componentes morfológicos das plantas de ervilha podem ser em função de uma distribuição mais equidistante de plantas na área, aumentando a eficiência de utilização de luz solar, água e nutrientes; melhor controle de plantas daninhas, devido ao fechamento mais rápido dos espaços disponíveis (EMBRAPA, 2008), permitindo que a planta se desenvolva melhor.

Por outro lado, os resultados deste estudo são contrários ao relatado por Gassi et al. (2009), que observaram aumento na massa fresca de vagens comercializáveis com o aumento do espaçamento entre plantas, e atribuíram esse incremento a menor competição das plantas também por fatores essenciais de crescimento como luz, água e nutrientes. O aumento da densidade de plantas até determinado limite é uma técnica usada com a finalidade de contribuir para a correta exploração do ambiente e do genótipo, com consequências no aumento do rendimento de grãos de uma cultura (EMBRAPA, 2008), como observado nesse trabalho, onde a ervilha respondeu positivamente a esta técnica, não ultrapassando esse limite.

As produções de massas frescas da parte aérea, da casca e da vagem não-comercial foram influenciadas significativamente apenas pelo número de fileiras no canteiro (Tabela 2), sendo que o tratamento com quatro fileiras de plantas no canteiro teve aumentos de $1,75 \mathrm{Mg} \mathrm{ha}^{-1}(+21,66 \%)$, 0,44 $\mathrm{Mg} \mathrm{ha}^{-1}(+17,53 \%)$, e 0,47 $\mathrm{Mg} \mathrm{ha}^{-1}(+26,40 \%)$, respectivamente, em relação ao com duas fileiras. 
Tabela 1. Massa fresca de grão e vagem comercial, massa seca de grão e vagem comercial, número de grão e vagem comercial de ervilha 'Luciana 50', cultivada sob duas, três e quatro fileiras de plantas no canteiro e com duas e três sementes por cova.

\begin{tabular}{|c|c|c|c|}
\hline \multirow[b]{2}{*}{ Número de sementes cova ${ }^{-1}$} & \multicolumn{3}{|c|}{ Fileiras entre plantas } \\
\hline & 2 & 3 & 4 \\
\hline \multicolumn{4}{|c|}{ Massa Fresca de Grão Comercial $\left(\mathrm{Mg} \mathrm{ha}^{-1}\right)$ C.V. $(\%)=16,28$} \\
\hline 2 & $1,76 \mathrm{~b} \mathrm{~B}$ & $2,22 \mathrm{a} A B$ & 2,51 a $\mathrm{A}$ \\
\hline 3 & 2,34 a A & 2,07 a A & 2,15 a A \\
\hline \multicolumn{4}{|c|}{ Massa Fresca de Vagem Comercial $\left(\mathrm{Mg} \mathrm{ha}^{-1}\right)$ C.V. $(\%)=16,56$} \\
\hline 2 & $3,55 \mathrm{~b} \mathrm{~B}$ & 4,42 a $\mathrm{AB}$ & 5,01 a $\mathrm{A}$ \\
\hline 3 & 4,70 a A & 4,31 a A & 4,70 a A \\
\hline \multicolumn{4}{|c|}{ Massa Seca de Grão Comercial $\left(\mathrm{Mg} \mathrm{ha}^{-1}\right)$ C.V. $(\%)=15,07$} \\
\hline 2 & $0,43 \mathrm{~b} \mathrm{~B}$ & 0,55 a $\mathrm{AB}$ & 0,65 a A \\
\hline 3 & 0,59 a A & 0,51 a A & 0,52 a A \\
\hline \multicolumn{4}{|c|}{ Massa Seca de Vagem Comercial $\left(\mathrm{Mg} \mathrm{ha}^{-1}\right)$ C.V. $(\%)=16,11$} \\
\hline 2 & $0,61 \mathrm{~b} \mathrm{~B}$ & 0,76 a $\mathrm{AB}$ & 0,90 a A \\
\hline 3 & 0,82 a $\mathrm{A}$ & 0,73 a $\mathrm{A}$ & 0,77 a A \\
\hline \multicolumn{4}{|c|}{ Número de Grão Comercial $\left(\mathrm{x} 1000\right.$ ha $\left.^{-1}\right)$ C.V. $(\%)=17,45$} \\
\hline 2 & 3167,35 b B & 3918,59 a $\mathrm{AB}$ & 4407,35 a A \\
\hline 3 & 4131,14 a A & 3716,10 a A & 3926,28 a A \\
\hline \multicolumn{4}{|c|}{ Número de Vagem Comercial $\left(\mathrm{x} 1000\right.$ ha $\left.^{-1}\right)$ C.V. $(\%)=15,37$} \\
\hline 2 & 671,69 b B & 835,70 a $\mathrm{AB}$ & 921,65 a A \\
\hline 3 & 921,27 a A & 801,93 a A & 859,47 a A \\
\hline
\end{tabular}

Médias seguidas pelas mesmas letras minúsculas nas colunas, não diferem entre si pelo teste $\mathrm{F}$, para número de sementes, e maiúsculas na linha, pelo teste de Tukey, para fileiras entre plantas, a $\mathrm{p}<0,05$.

Fonte: Elaboração dos autores.

Tabela 2. Massa fresca da parte aérea, casca e vagem não-comercial de ervilha 'Luciana 50', cultivada sob duas, três e quatro fileiras de plantas no canteiro e com duas e três sementes por cova.

\begin{tabular}{lccc}
\hline & \multicolumn{3}{c}{ Massa fresca (Mg ha $\left.\mathbf{- 1}^{-1}\right)$} \\
\hline Fatores em estudo & Parte aérea & Casca & Vagem não-comercial \\
\hline Fileiras & & & $1,31 \mathrm{~b}$ \\
\hline Duas & $6,33 \mathrm{~b}$ & $2,07 \mathrm{~b}$ & $1,40 \mathrm{ab}$ \\
Três & $7,02 \mathrm{ab}$ & $2,22 \mathrm{ab}$ & $1,78 \mathrm{a}$ \\
Quatro & $8,08 \mathrm{a}$ & $2,51 \mathrm{a}$ & \\
\hline Número de sementes & & & $1,43 \mathrm{a}$ \\
\hline 2 & $6,77 \mathrm{a}$ & $2,16 \mathrm{a}$ & $1,57 \mathrm{a}$ \\
3 & $7,53 \mathrm{a}$ & $2,38 \mathrm{a}$ & 25,82 \\
\hline C.V. (\%) & 16,72 & 16,48 & \\
\hline
\end{tabular}

Médias seguidas pelas mesmas letras nas colunas não diferem entre si pelo teste F, para número de sementes e pelo teste de Tukey, para fileiras a $\mathrm{p}<0,05$.

Fonte: Elaboração dos autores.

Com a maior a densidade de plantas (quatro fileiras), obtiveram-se as maiores produções. Os aumentos obtidos foram devidos, provavelmente, ao aumento do número de plantas por hectare e não pelo aumento da massa individual de cada planta.
Isso porque a maximização da produção depende, dentre outros, da adequada distribuição espacial das plantas na área, em conformidade com as características da espécie (HARDER; HEREDIA ZÁRATE; VIEIRA, 2005). 
As produções de massas secas da parte aérea, da vagem comercial e não-comercial e da casca foram influenciadas significativamente pelo número de fileiras (Tabela 3), obtendo as maiores produções no cultivo com quatro fileiras de plantas, com aumentos de $24,19 \%, 20,00 \%$ e $22,22 \%$, respectivamente, em relação a duas fileiras. $\mathrm{O}$ número de sementes por cova influenciou significativamente a massa seca da parte aérea, obtendo a maior produção com o uso de três sementes por cova, que superou em $0,17 \mathrm{Mg}$ $\mathrm{ha}^{-1}(+18,08 \%)$ ao cultivo com duas sementes por cova. Por esses resultados supõe-se que o menor espaçamento não induziu à pressão populacional que diminuísse a capacidade produtiva da planta, devido à competição por fatores de crescimento tais como luz, nutrientes e água, o que poderia resultar em decréscimo da produção (MARSCHNER, 2005).

Tabela 3. Massa seca da parte aérea, casca e vagem não-comercial de ervilha 'Luciana 50', cultivada sob duas, três e quatro fileiras de plantas no canteiro e com duas e três sementes por cova.

\begin{tabular}{lccc}
\hline & \multicolumn{2}{c}{ Massa seca $\left(\mathbf{M g} \mathbf{~ h a}^{-1}\right)$} \\
\hline Fatores em estudo & Parte aérea & Casca & Vagem não-comercial \\
\hline Fileiras & & & $0,42 \mathrm{~b}$ \\
\hline Duas & $0,94 \mathrm{~b}$ & $0,20 \mathrm{~b}$ & $0,42 \mathrm{~b}$ \\
Três & $1,09 \mathrm{ab}$ & $0,21 \mathrm{ab}$ & $0,54 \mathrm{a}$ \\
Quatro & $1,24 \mathrm{a}$ & $0,25 \mathrm{a}$ & $0,46 \mathrm{a}$ \\
\hline Número de sementes & & & $0,46 \mathrm{a}$ \\
\hline 2 & $0,77 \mathrm{~b}$ & $0,21 \mathrm{a}$ & 21,74 \\
\hline C.V. (\%) & $0,94 \mathrm{a}$ & $0,23 \mathrm{a}$ & 18,85 \\
\hline
\end{tabular}

Médias seguidas pelas mesmas letras nas colunas não diferem entre si pelo teste F, para número de sementes e pelo teste de Tukey, para fileiras a $\mathrm{p}<0,05$.

Fonte: Elaboração dos autores.

O número de vagens não-comerciais foi influenciado significativamente pelo número de fileiras, obtendo a maior produção quando se utilizou quatro fileiras de plantas (Tabela 4), superando em 184.310 ha-1 ao cultivo com duas fileiras de plantas e $75.830 \mathrm{ha}^{-1}$ ). Andreoli e Fontes (1980), estudando a produtividade das cultivares de ervilha Elegante e Petrolini em função do espaçamento entre fileiras (10; 20 e $40 \mathrm{~cm})$ e da população de plantas (250; 500; 1.000 e 2.000 mil plantas ha-1), no Distrito Federal, concluíram que, à medida que a população aumentou, o número de vagens planta $^{-1}$ diminuiu bruscamente, ao contrário do que se observou nesse trabalho, onde esses aumentos obtidos pela maior densidade de plantas (quatro fileiras) foram atribuídos pelo aumento da população de plantas, onde há um aumento na massa fresca da parte aérea (Tabela 2), consequentemente houve um aumento na absorção de radiação, sem competição, que é importante variável determinante do crescimento das plantas e amplamente utilizada nos modelos matemáticos de produtividade (PEREIRA et al., 2008).

O número de vagem não-comercial foi influenciado significativamente apenas pelo número de plantas no canteiro. Já o diâmetro de grãos, o comprimento e o diâmetro de vagens comerciais não foram influenciados significativamente pelo número de fileiras e nem pelo número de sementes por cova (Tabela 4). Esses resultados mostram-se coerentes com o exposto por Larcher (2000), sobre os sistemas ecológicos serem capazes de se autoregular com base no equilíbrio das relações de interferência e na grande capacidade de adaptação do organismo individual e das populações. 
Tabela 4. Número de vagem não-comercial, diâmetro de grão, comprimento e diâmetro de vagem comercial de ervilha 'Luciana 50', cultivada sob duas, três e quatro fileiras de plantas no canteiro e com duas e três sementes por cova.

\begin{tabular}{lcccc}
\hline & \multicolumn{2}{c}{ Vagem não-comercial } & \multicolumn{2}{c}{ Vagem comercial } \\
\hline Fatores em estudo & $\begin{array}{c}\text { Número } \\
\left(\mathbf{h a}^{-1}\right)\end{array}$ & $\begin{array}{c}\text { Diâmetro de grão } \\
(\mathbf{m m})\end{array}$ & $\begin{array}{c}\text { Comprimento de vagem } \\
(\mathbf{m m})\end{array}$ & $\begin{array}{c}\text { Diâmetro de } \\
\text { vagem } \mathbf{( m m})\end{array}$ \\
\hline Fileiras & & & & $12,34 \mathrm{a}$ \\
\hline Duas & $504.130 \mathrm{~b}$ & $9,20 \mathrm{a}$ & $71,74 \mathrm{a}$ & $11,34 \mathrm{a}$ \\
Três & $612.610 \mathrm{~b}$ & $9,36 \mathrm{a}$ & $71,02 \mathrm{a}$ & $11,69 \mathrm{a}$ \\
Quatro & $688.440 \mathrm{a}$ & $9,28 \mathrm{a}$ & $72,87 \mathrm{a}$ & $11,69 \mathrm{a}$ \\
\hline Número de sementes & & & & $11,90 \mathrm{a}$ \\
\hline 2 & $592.250 \mathrm{a}$ & $9,27 \mathrm{a}$ & $71,86 \mathrm{a}$ & 13,41 \\
\hline
\end{tabular}

Médias seguidas pelas mesmas letras nas colunas não diferem entre si pelo teste F, para número de sementes e pelo teste de Tukey, para fileiras a $\mathrm{p}<0,05$.

Fonte: Elaboração dos autores.

\section{Avaliação agroeconômica}

Os custos de produção para 1,0 ha de ervilha 'Luciana 50' variaram em R\$ 4.168,21 entre o menor custo (R $\$ 5.737,68$ ), que correspondeu ao cultivo com duas fileiras de plantas e duas sementes por cova (Tabela 5), e o maior custo ( $\mathrm{R} \$ 10.196,69)$, que correspondeu ao cultivo com quatro fileiras de plantas e três sementes por cova (Tabela 6).

Do custo total de produção, os custos variáveis representaram $80,39 \% \quad(\mathrm{R} \$ 4.612,52)$, para o tratamento que se obteve o menor custo (R\$ $5.737,68)$, que foi com duas fileiras de plantas e duas sementes por cova, e 82,46\% (R\$ 8.407,92) para o de maior custo ( $\mathrm{R} \$ 10.196,69)$, que foi com quatro fileiras de plantas e três sementes por cova. A mão-de-obra foi responsável por gastos entre $37,91 \%$ ( $\$$ \$ 2.175,00) para duas fileiras de plantas e duas sementes por cova e $21,33 \%$ para quatro fileiras de plantas e três sementes por cova. Esses dados ressaltam a importância da cultura, como atividade geradora de emprego no meio rural, por meio do uso de sua mão-de-obra. Em relação aos insumos e maquinários, os custos representaram, respectivamente, $33,07 \%(\mathrm{R} \$ 1.897,50)$ e $9,41 \%$ (R\$ 540,00) no tratamento com duas fileiras de plantas e duas sementes por cova, e entre 55,83\% $(\mathrm{R} \$ 5.692,92)$ e $5,30 \%(\mathrm{R} \$ 540,00)$ para quatro fileiras de plantas e três sementes por cova.
Os custos fixos e outros adicionais (imprevistos e administração) variaram entre 5,44\% (R\$ 312,00) e $12,06 \%$ (R\$ 691,87), no tratamento com duas fileiras de plantas e duas sementes por cova e 3,06\% $(\mathrm{R} \$ 312,00)$ e $12,37 \%(\mathrm{R} \$ 1.261,18)$ com quatro fileiras e duas sementes por cova, respectivamente.

Considerando a produção média obtida em cada tratamento, a estimativa da renda líquida mostrou que o cultivo da ervilha 'Luciana 50' utilizando na semeadura duas sementes por cova e quatro fileiras de plantas foi a melhor, tanto para vagens comerciais (Tabela 7) como para grãos comerciais (Tabela 8). A renda líquida de vagens comerciais superou em R\$ 5.070,42 (aumento de 29,68\%) à renda obtida com a utilização de duas fileiras de plantas e com duas sementes por cova, que foi a menor produtividade. Já a renda líquida de grãos comerciais superou em $\mathrm{R} \$ 5.829,43$ (aumento de 34,02\%) à renda obtida com a utilização de quatro fileiras de plantas e com três sementes por cova. Os resultados obtidos para a renda líquida confirmam a necessidade de se estudar economicamente a aplicação de técnicas agrícolas, em especial as relacionadas com população de plantas, para se conhecer detalhadamente a estrutura produtiva da atividade e das alterações para o aumento de sua eficiência (PEREZ JÚNIOR; OLIVEIRA; COSTA, 2006). 
Tabela 5. Custos de produção de um hectare da ervilha 'Luciana $\mathrm{N}^{\mathrm{o}} 50$ 'com duas sementes por cova e com diferentes fileiras de plantas no canteiro.

\begin{tabular}{|c|c|c|c|c|c|c|}
\hline \multirow{3}{*}{$\begin{array}{l}\text { Componentes } \\
\text { do custo }\end{array}$} & \multicolumn{6}{|c|}{ Número de fileiras } \\
\hline & \multicolumn{2}{|c|}{2 fileiras } & \multicolumn{2}{|c|}{3 fileiras } & \multicolumn{2}{|c|}{4 fileiras } \\
\hline & Quantidade & Custo (R\$) & Quantidade & Custo (R\$) & Quantidade & Custo (R\$) \\
\hline \multicolumn{7}{|l|}{ A-Custos variáveis } \\
\hline \multicolumn{7}{|l|}{ A1 - Insumos } \\
\hline Sementes $^{1}$ & $75,9 \mathrm{~kg}$ & $1.897,50$ & $113,85 \mathrm{~kg}$ & $2.846,46$ & $151,80 \mathrm{~kg}$ & $3.795,28$ \\
\hline \multicolumn{7}{|l|}{ A2 - Mão-de-obra } \\
\hline Semeadura & $20 \mathrm{D} / \mathrm{H}$ & 500,00 & $20 \mathrm{D} / \mathrm{H}$ & 500,00 & $20 \mathrm{D} / \mathrm{H}$ & 500,00 \\
\hline Irrigação & $15 \mathrm{D} / \mathrm{H}$ & 375,00 & $15 \mathrm{D} / \mathrm{H}$ & 375,00 & $15 \mathrm{D} / \mathrm{H}$ & 375,00 \\
\hline Capinas & $22 \mathrm{D} / \mathrm{H}$ & 550,00 & $22 \mathrm{D} / \mathrm{H}$ & 550,00 & $22 \mathrm{D} / \mathrm{H}$ & 550,00 \\
\hline Colheita & $30 \mathrm{D} / \mathrm{H}$ & 750,00 & $30 \mathrm{D} / \mathrm{H}$ & 750,00 & $30 \mathrm{D} / \mathrm{H}$ & 750,00 \\
\hline \multicolumn{7}{|l|}{ A3 - Maquinários } \\
\hline Bomba de irrigação & $30,0 \mathrm{~h}$ & 300,00 & $30,0 \mathrm{~h}$ & 300,00 & $30,0 \mathrm{~h}$ & 300,00 \\
\hline Trator & $4,0 \mathrm{~h}$ & 240,00 & $4,0 \mathrm{~h}$ & 240,00 & $4,0 \mathrm{~h}$ & 240,00 \\
\hline Total A (TA) (R\$) & & $4.612,50$ & & $5.561,46$ & & $6.510,28$ \\
\hline \multicolumn{7}{|l|}{ B - Custos Fixos } \\
\hline Benfeitoria & 108 dias & 162,00 & 108 dias & 162,00 & 108 dias & 162,00 \\
\hline Remuneração da terra & 1,0 ha & 150,00 & 1,0 ha & 150,00 & 1,0 ha & 150,00 \\
\hline Total B (R\$) & -- & 312,00 & -- & 312,00 & -- & 312,00 \\
\hline \multicolumn{7}{|l|}{ C - Outros custos } \\
\hline Imprevistos (10\% TA) & -- & 461,25 & -- & 556,14 & -- & 651,02 \\
\hline Administração (5\% TA) & -- & 230,62 & -- & 278,07 & -- & 325,51 \\
\hline Total C $(\mathrm{R} \$)$ & -- & 691,87 & -- & 834,21 & -- & 976,53 \\
\hline TOTAL $(A+B+C)$ & -- & $5.616,37$ & -- & $6.707,67$ & -- & $7.798,81$ \\
\hline Juro trimestral $(2,16 \%)$ & 1 & 121,31 & 1 & 144,88 & 1 & 168,45 \\
\hline TOTAL GERAL & -- & $5.737,68$ & -- & $6.832,12$ & -- & $7.967,26$ \\
\hline
\end{tabular}

Adaptado de Terra et al. (2006) e Heredia Zárate et al. (2012). Custos dia homem ${ }^{-1} \mathrm{D} / \mathrm{H}=\mathrm{R} \$ 25,00$.

Fonte: Elaboração dos autores.

Tabela 6. Custos de produção de um hectare da ervilha 'Luciana $\mathrm{N}^{\circ} 50$ 'com três sementes por cova e com diferentes fileiras de plantas no canteiro.

\begin{tabular}{|c|c|c|c|c|c|c|}
\hline \multirow{3}{*}{$\begin{array}{l}\text { Componentes } \\
\text { do custo }\end{array}$} & \multicolumn{6}{|c|}{ Número de fileiras } \\
\hline & \multicolumn{2}{|c|}{2 fileiras } & \multicolumn{2}{|c|}{3 fileiras } & \multicolumn{2}{|c|}{4 fileiras } \\
\hline & Quantidade & Custo (R\$) & Quantidade & Custo (R\$) & Quantidade & Custo (R\$) \\
\hline \multicolumn{7}{|l|}{ A-Custos variáveis } \\
\hline \multicolumn{7}{|l|}{ A1 - Insumos } \\
\hline Sementes $^{1}$ & $113,85 \mathrm{~kg}$ & $2.846,46$ & $170,77 \mathrm{~kg}$ & $4.269,69$ & $227,70 \mathrm{~kg}$ & $5.692,92$ \\
\hline \multicolumn{7}{|l|}{ A2 - Mão-de-obra } \\
\hline Semeadura & $20 \mathrm{D} / \mathrm{H}$ & 500,00 & $20 \mathrm{D} / \mathrm{H}$ & 500,00 & $20 \mathrm{D} / \mathrm{H}$ & 500,00 \\
\hline Irrigação & $15 \mathrm{D} / \mathrm{H}$ & 375,00 & $15 \mathrm{D} / \mathrm{H}$ & 375,00 & $15 \mathrm{D} / \mathrm{H}$ & 375,00 \\
\hline Capinas & $22 \mathrm{D} / \mathrm{H}$ & 550,00 & $22 \mathrm{D} / \mathrm{H}$ & 550,00 & $22 \mathrm{D} / \mathrm{H}$ & 550,00 \\
\hline Colheita & $30 \mathrm{D} / \mathrm{H}$ & 750,00 & $30 \mathrm{D} / \mathrm{H}$ & 750,00 & $30 \mathrm{D} / \mathrm{H}$ & 750,00 \\
\hline \multicolumn{7}{|l|}{ A3 - Maquinários } \\
\hline Bomba de irrigação & $30,0 \mathrm{~h}$ & 300,00 & $30,0 \mathrm{~h}$ & 300,00 & $30,0 \mathrm{~h}$ & 300,00 \\
\hline Trator & $4,0 \mathrm{~h}$ & 240,00 & $4,0 \mathrm{~h}$ & 240,00 & $4,0 \mathrm{~h}$ & 240,00 \\
\hline Total A $(\mathrm{R} \$)$ & & $5.561,46$ & & $6.984,69$ & & $8.407,92$ \\
\hline
\end{tabular}


continuação

\begin{tabular}{lcccccc}
\hline B - Custos Fixos & \multicolumn{7}{c}{} \\
\hline Benfeitoria & 108 dias & 162,00 & 108 dias & 162,00 & 108 dias & 162,00 \\
Remuneração da terra & 1,0 ha & 150,00 & 1,0 ha & 150,00 & 1,0 ha & 150,00 \\
\hline Total B $(\mathrm{R} \$)$ & -- & $\mathbf{3 1 2 , 0 0}$ & -- & $\mathbf{3 1 2 , 0 0}$ & -- & $\mathbf{3 1 2 , 0 0}$ \\
\hline C-Outros custos & & & & & & \\
\hline Imprevistos $(10 \% \mathrm{TA})$ & -- & 556,14 & -- & 698,46 & -- & 840,79 \\
\hline Administração $(5 \% \mathrm{TA})$ & -- & 278,07 & -- & 349,23 & -- & 420,39 \\
\hline Total C (R) & -- & $\mathbf{8 3 4 , 2 1}$ & -- & $\mathbf{1 . 0 4 7 , 6 9}$ & -- & $\mathbf{1 . 2 6 1 , 1 8}$ \\
\hline TOTAL (A+B+C) & -- & $\mathbf{6 . 7 0 7 , 6 7}$ & -- & $\mathbf{8 . 3 4 4 , 3 8}$ & -- & $\mathbf{9 . 9 8 1 , 1 0}$ \\
\hline Juro trimestral $(2,16 \%)$ & 1 & 144,88 & 1 & 180,23 & 1 & 215,59 \\
\hline TOTAL GERAL & -- & $\mathbf{6 . 8 5 2 , 5 5}$ & -- & $\mathbf{8 . 5 2 4 , 6 1}$ & -- & $\mathbf{1 0 . 1 9 6 , 6 9}$ \\
\hline
\end{tabular}

Adaptado de Terra et al. (2006) e Heredia Zárate et al. (2012). Custos dia homem ${ }^{-1} \mathrm{D} / \mathrm{H}=\mathrm{R} \$ 25,00$.

Fonte: Elaboração dos autores.

Tabela 7. Produtividade, renda bruta, custo da semente e renda líquida de vagens comerciais de ervilha 'Luciana 50', cultivada sob duas, três e quatro fileiras de plantas no canteiro e com duas e três sementes por cova.

\begin{tabular}{|c|c|c|c|c|c|}
\hline \multicolumn{2}{|c|}{ Fatores em estudo } & \multirow{2}{*}{$\begin{array}{l}\text { Produtividade } \\
\qquad\left(\mathrm{kg} \mathrm{ha}^{-1}\right)\end{array}$} & \multirow{2}{*}{$\begin{array}{l}\text { Renda bruta }{ }^{1} \\
\text { (R\$) }\end{array}$} & \multirow{2}{*}{$\begin{array}{c}\text { Custo }^{2} \\
(\mathrm{R} \$)\end{array}$} & \multirow{2}{*}{$\begin{array}{c}\text { Renda líquida } \\
\text { (R\$) }\end{array}$} \\
\hline $\mathrm{N}^{o}$ de fileiras & Sementes por cova & & & & \\
\hline \multirow{2}{*}{ Duas } & 2 & 3.550 & $17.750,00$ & $5.737,68$ & $12.012,32$ \\
\hline & 3 & 4.700 & $23.500,00$ & $6.852,55$ & $16.647,45$ \\
\hline \multirow{2}{*}{ Três } & 2 & 4.420 & $22.100,00$ & $6.832,12$ & $15.267,88$ \\
\hline & 3 & 4.310 & $21.550,00$ & $8.524,61$ & $13.025,39$ \\
\hline \multirow{2}{*}{ Quatro } & 2 & 5.010 & $25.050,00$ & $7.967,26$ & $17.082,74$ \\
\hline & 3 & 4.700 & $23.500,00$ & $10.196,69$ & $13.303,31$ \\
\hline
\end{tabular}

${ }^{1} \mathrm{R} \$ 5,00 \mathrm{~kg}^{-1}$. Preço pago ao produtor de ervilha de vagens na feira de central em Dourados-MS, dia 12/01/2011.

${ }^{2}$ Custo de semente 'Luciana 50': R\$ 25,00. Fonte: Coasf, Dourados, MS.

Fonte: Elaboração dos autores.

Tabela 8. Produtividade, renda bruta, custo da semente e renda líquida de grãos comerciais de ervilha 'Luciana 50', cultivada sob duas, três e quatro fileiras de plantas no canteiro e com duas e três sementes por cova.

\begin{tabular}{lccccc}
\hline \multicolumn{2}{c}{ Fatores em estudo } & $\begin{array}{c}\text { Produtividade } \\
\left(\mathrm{kg} \mathrm{ha}^{-1}\right)\end{array}$ & $\begin{array}{c}\text { Renda bruta } \\
(\mathrm{R} \$)\end{array}$ & $\begin{array}{c}\text { Custo }^{2} \\
(\mathrm{R} \$)\end{array}$ & $\begin{array}{c}\text { Renda líquida } \\
(\mathrm{R} \$)\end{array}$ \\
\cline { 1 - 2 } No de fileiras & Sementes por cova & 1.760 & $17.600,00$ & $5.737,68$ & $11.862,32$ \\
\multirow{2}{*}{ Duas } & 2 & 2.340 & $23.340,00$ & $6.852,55$ & $16.487,45$ \\
\hline \multirow{2}{*}{ Três } & 3 & 2.220 & $22.220,00$ & $6.832,12$ & $15.387,88$ \\
& 2 & 2.070 & $20.700,00$ & $8.524,61$ & $12.175,39$ \\
\hline \multirow{2}{*}{ Quatro } & 3 & 2.510 & $25.100,00$ & $7.967,26$ & $17.132,74$ \\
& 2 & 2.150 & $21.500,00$ & $10.196,69$ & $11.303,31$ \\
\hline
\end{tabular}

${ }^{1} \mathrm{R} \$ 10,00 \mathrm{~kg}^{-1}$. Preço pago ao produtor de ervilha de vagens na feira de central em Dourados-MS, dia 12/01/2011.

${ }^{2}$ Custo de sementes 'Luciana 50’: R\$ 25,00. Fonte: Coasf, Dourados, MS.

Fonte: Elaboração dos autores. 


\section{Conclusões}

Para se obterem maiores produtividades de vagens e grãos comerciais o cultivo de ervilha 'Luciana 50' deve ser feito com arranjo de quatro fileiras de plantas no canteiro e com 2 sementes $\operatorname{cova}^{-1}$.

O menor custo de produção correspondeu ao cultivo de ervilha com duas fileiras entre plantas e 2 sementes por cova ${ }^{-1}$, porém as maiores rendas bruta e líquida foram obtidas no cultivo com quatro fileiras de plantas e 2 sementes cova ${ }^{-1}$.

\section{Agradecimentos}

Ao CNPQ, pela bolsa concedida.

\section{Referências}

ANDREOLI, C.; FONTES, R. Z. Influência do espaçamento e da população de plantas na produtividade de sementes de ervilha no Distrito Federal. Revista Brasileira de Sementes, Brasília, v. 2, n. 1, p. 89-96, 1980.

ARGENTA, G. S.; SILVA, P. R. F.; BORTOLINI, G. G.; FORSTHOFER, E. L.; MANJABOSCO, E. A.; NETO, V. B. Resposta de híbridos simples de milho à redução do espaçamento entre linhas. Pesquisa Agropecuária Brasileira, Brasília, v. 36, n. 1, p. 1-8, 2001.

EMPRESA BRASILEIRA DE PESQUISA AGROPECUÁRIA - EMBRAPA. Centro Nacional de Pesquisa de Hortaliças. Ervilha para produção de grãos verdes. Brasília: Embrapa Hortaliças, 2012. Disponível em: $<$ www.cnph.embrapa.br/cultivares/ervilha $>$. Acesso em: 20 jun. 2012.

Centro Nacional de Pesquisa de Solos. Sistema brasileiro de classificação de solos. 2. ed. Brasília: Embrapa Produção de Informação. Rio de Janeiro: Embrapa Solos, 2006. 306 p.

Sistemas de produção. Cultivo do milho. Brasília: Embrapa Milho e Sorgo. 2008. Disponível em: $<\quad h t t p s: / / w w w . s p o . c n p t i a . e m b r a p a . b r / c o n t e u d o ? p \_p$ $\mathrm{id}=$ conteudoportlet_WAR_sistemasdeproducaolf6_1ga 1 ceportlet\&p_p_lifecycle $=0 \& p \_p \_$state $=$normal $\& p \_p \_$ $\operatorname{mode}=v i e w \& p \_p \_c o l \_i d=$ column $-1 \& p \_p \_c o l$ count $=1 \& p \_r$ _p_-76293187_sistemaProducaoId $=3821$ \&p_r_p_-996514994_topicoId $=1309>$ >. Acesso em: 24 abr. 2014 .
FILGUEIRA, F. A. R. Novo manual de olericultura: agrotecnologia moderna na produção e comercialização de hortaliças. 3. ed. Viçosa, 2008. 421 p.

GASSI, R. P.; HEREDIA ZÁRATE, N. A.; VIEIRA, M. C.; GOMES, H. E.; MUNARIN, E. E.; RECH, J. Espaçamentos entre plantas e número de fileiras no canteiro na produção de ervilha. Horticultura Brasileira, Brasília, v. 27, n. 4, p. 549-552, 2009.

HARDER, W. C.; HEREDIA ZÁRATE, N. A.; VIEIRA, M. C. Produção e renda bruta de rúcula (Eruca sativa Mill.) 'Cultivada' e de almeirão (Cichorium intybus L.) 'Amarelo', em cultivo solteiro e consorciado. Ciência e Agrotecnologia, Lavras, v. 29, n. 4, p. 775-785, 2005.

HEREDIA ZÁRATE, N. A.; GASSI, R. P.; VIEIRA, M. C.; TABALDI, L. A.; TORALES, E. P.; FACCIN, F. C. Espaçamentos entre plantas e cobertura do solo com cama-de-frango na produção de ervilhas. Bragantia, Campinas, v. 71, n. 1, p. 42-46, 2012.

HEREDIA ZÁRATE, N. A.; VIEIRA, M. C.; GRACIANO, J. D.; FIGUEIREDO, P. G.; BLANS, N. B.; CURIONI, B. M. Produtividade de mandioquinhasalsa sob diferentes densidades de plantio e tamanho de mudas. Ciência e Agrotecnologia, Lavras, v. 33, n. 1, p. 139-143, 2009.

INSTITUTO AGRONÔMICO DE CAMPINAS IAC. Centro de Análise e Pesquisa Tecnológica do Agronegócio de Grãos e Fibras. Campinas: IAC, 2011. Disponível em: <http://www.iac.sp.gov.br/Tecnologias/ ErvilhaGraos/ErvilhaGraos.htm>. Acesso em: 20 jun. 2012.

ISLAM, M. S.; RAHMAN, M. A.; SALAM, M. A.; MASUM, A. S. M. H.; RAHMAN, M. H. Growth and vegetable pod yield of edible podded pea as influenced by sowing time and plant density. Journal of Biological Sciences, Bangladesh, v. 10, n. 2, p. 706-709, 2002.

LARCHER, W. Ecofisiologia vegetal. São Carlos: RiMa Artes e Textos, 2000. 531 p.

MARSCHNER, H. Mineral nutrition of higher plants. 2. ed. Orlando: Academic Press, 2005. 889 p.

MELO, A. S.; COSTA, B. C.; BRITO, M. E. B.; AGUIAR NETTO, A. O.; VIÉGAS, P. R. A. Custo e rentabilidade na produção de batata-doce nos perímetros irrigados de Itabaiana-Sergipe. Pesquisa Agropecuária Tropical, Goiânia, v. 39, n. 2, p. 119-123, 2009.

PEIXOTO, C. P.; GONÇALVES, J. A.; PEIXOTO, M. F. S. P.; CARMO, D. O. Características agronômicas e produtividade de amendoim em diferentes espaçamentos e épocas de semeadura no Recôncavo Baiano. Bragantia, Campinas, v. 67, n. 3, p. 673-684, 2008. 
PEREIRA, A. P.; VILLA NOVA, N. A.; RAMOS, V. J.; PEREIRA, A. R. Potato potential yield based on climatic elements and cultivar characteristics. Bragantia, Campinas, v. 67, n. 2, p. 327-334, 2008.

PEREZ JÚNIOR, J. H.; OLIVEIRA, L. M.; COSTA, R. G. Gestão estratégica de custos. 5. ed. São Paulo: Atlas, 2006. 378 p.
TERRA, E. R.; HEREDIA ZÁRATE, N. A.; VIEIRA, M. C. MENDONÇA, P. S. M. Proposta de cálculo e forma de adubação, com e sem amontoa, para a produção e renda do milho Superdoce 'Aruba'. Acta Scientiarum: Agronomy, Maringá, v. 28, n. 1, p. 75-82, 2006.

VIEIRA, R. F.; RESENDE, M. A. V.; SANTOS, C. M. Épocas de plantio de ervilha em Patos de Minas, Uberaba e Janaúba, Minas Gerais. Ciência e Agrotecnologia, Lavras, v. 24, n. 1, p. 74-80, 2000. 
